\title{
Air Distribution Analysis in Drying Tumpeng Process with Dry Racking Machine Type
}

\author{
I Made Arsawan ${ }^{1}$, I Putu Sastra Negara ${ }^{2}$, Gede Santosa ${ }^{3}$, I Gede Oka Pujiadi ${ }^{4}$, Ketut Bangsa ${ }^{5}$ \\ Mechanical Engineering Department \\ Bali State Polytechnic \\ Badung-Bali, Indonesia \\ ${ }^{1}$ madearsawan@pnb.ac.id, ${ }^{2}$ putusastranegara@pnb.ac.id, ${ }^{3}$ gedesantosa@pnb.ac.id, ${ }^{4}$ gedeokapujiadi@pnb.ac.id, \\ ${ }^{5}$ ketutbangsa@pnb.ac.id
}

\begin{abstract}
The Balinese people cannot be separated from their cultural and religious customs. The religious procession for Balinese people is conducted to express our gratitude to Ida Sang Hyang Widi Wasa (The Almighty God) for the gift he has given. One of the ceremonial facilities used is tumpeng, and in aseries of ceremony, a lot of tumpeng is usually needed. As the result, many people turn this opportunity into a business. One of the villages in Gianyar regency, namely the Buruan village, Blahbatuh subdistrict, the community has a lot to do with their tumpeng penet business. In this village, the craftsmen still encounter many obstacles in the drying process of the cone. Nowadays, the drying process is still using the manual method by drying it under the direct sunlight. The disadvantage of this process is that this process takes long enough time and can only be done in the season. For this reason, some efforts are required to make in order to help the craftsmen of tumpeng increase their productivity, in which the distribution of air in the drying process of tumpeng will be tested in this research by using a multilevel rack type drying machine. The purpose of this research is to get the design of an air circulation system which is evenly distributed in the drying chamber of the tumpeng drying machine with multilevel rack type. The method usedin this study is to make a multilevel rack type drying machine with 6 levels with an LPG gas source as a test tool. By using the existing test equipment several types of air distribution will be tried to be created to get an even air distribution system in the drying chamber. Each thermocouple will be installed on a rack to find out the temperature that occurs on each rack. From the results of the research, it turns out that the rack temperature in the lowest rack position (near the heat source) produces the highest temperature, and the rack above it has a lower temperature with an average of $\Delta T 35^{\circ} \mathrm{C}$ this data is obtained on the system without the circulation of hot air in the drying chamber. After the process of air distribution in the drying chamber, even though the lowest rack has the highest temperature, yet the differrence of temperature between the shelves is not too large; the average between shelves reaches $10{ }^{\circ} \mathrm{C}$.
\end{abstract}

Keywords-Drying Machine; Multilevel Rack Type; Even Air Distribution

\section{INTRODUCTION}

The existence of Balinese people cannot be separated from their cultural and religious customs. The religious procession for Balinese people is conducted as an expression of gratitude to Ida Sang Hyang Widi Wasa (The Almighty God) for the gift he has given. One of the ceremonial means used is tumpeng, and there are a lot of tumpeng required in a series of ceremonies. Many people, then, turn this opportunity into bussiness that can provide income for the business actor.

This Tumpeng business is often found in the Buruan village, Belahbatuh sub-districts. In this village, the craftsmen still encaunter many obstacles in the drying process of tumpeng. Many innovations have been made by the entrepreneurs in order to increase their productivity, such as in the drying process in which, initially, it only relies on the sun's heat and now the source energy from gas stove has been used for the drying process. Drying systems which solely rely on solar energy can be done only in the dry season, while in the rainy season the solar energy is not optimal, so that in the drying process many people will experience problems such as tumpeng will be in mildew, so it is not feasible to market. In the process of drying with equipment designed by the craftsmen themselves still experience obstacles must move position container tumpeng alternately toward under close stove and sometimes when tumpeng can be charred because of the move positionment tumpeng and this process requires operators who wait for the drying process to end.

Some efforts are required in order to help the craftsmen of tumpeng increase their productivity, in which the problem of air distribution in the drying chamber of a Tumpeng dryer will be examined .

The problem formulated in this study is how the influence of the position of air circulation to the room temperature of the Tumpeng dryer machine. The purpose of this study was to determine the temperature of the drying chamber on each rack of a cone drying machine if the position of the hot air distribution was varied. The benefit of this research is to obtain an even distribution of air at each level of the tumpeng drying machine rack. 


\section{RELATED RESEARCH}

\section{A. Heat Transfer}

Heat transfer can be defined as the transfer of energy from one region to another as a result of temperature differences between these regions. The matter of heat flow is universal which is related to gravitational pull. In general there are three different ways of heat transfer, namely: conduction (conduction; known as conduct), radiation (radiation) and convection (convection; known as ilian). To be more precise, only conduction and radiation can be classified as heat transfer processes, because only both of these mechanisms depend on the temperature difference. Whereas convection does not exactly meet the definition of heat transfer, because of its implementation depending on the mechanical mass transport as well. However, since convection also results in the transfer of energy from areas with higher temperatures to areas with lower temperatures, the term "heat transfer by means of convection" has been generally accepted.

\section{Conduction Heat Transfer / conductivity}

Conduction is a process whereby heat flows from high temperature areas to areas with lower temperatures in one medium (solid, liquid or gas) or between different mediums which are in direct contact without large enough molecular displacements according to kinetic theory. The element's temperature is proportional to the average kinetic energy of the molecules that makes up the element. The energy possessed by an element of substance is caused by the speed and relative position of the molecules - the molecules are called inner energy. The transfer of energy can take place with an elastic impact, for example in a fluid or by mixing (diffusion / diffusion) of electrons moving rapidly from an area with a high temperature to a lower temperature (e.g. metal). Conduction is the only mechanism by which heat can flow in non translucent solids.

\section{Radiation / Glow}

Radiation is the process in which heat flows from a high temperature object to a low temperature object, if the objects are separated in space, even if there is a vacuum between them. All objects emit continuous radiant heat. The intensity of the emission depends on temperature and surface properties. Radiation energy moves at the speed of light (3x108 m / s) and its symptoms resemble light radiation. According to electromagnetic theory, light radiation and thermal radiation differ only in their respective wavelengths.

\section{Convection / Ilian}

Convection is the process of transporting energy with the combined work of heat conduction, energy storage and mixing movements. Convection is very important as a mechanism of energy transfer between the surfaces of solid, liquid or gas objects. Heat transfer by convection is classified in free convection and forced convection according to how it moves the flow. When the mixing movement takes place solely as a result of differences in density caused by temperature gradients, it is called free or natural convection. If the mixing movement is caused by an external device such as a pump or fan, the process is called forced convection. The effectiveness of heat transfer by means of convection depends in large part on the motion of mixing fluid. Consequently the study of convection heat transfer is based on the knowledge of the characteristics of fluid flow.

\section{B. Drying Process}

The drying process is a process of heat transfer and water vapor simultaneously, which requires heat energy to evaporate the water content removed from the surface of the material, which is dried by the drying medium in the form of heat generated by the collector. The events that occur during the scouring process are:

1. Understanding process heat, which is the process that occurs because the temperature difference, heat flows will increase temperature more material low, cause press water vapor inside ingredients more high from press water vapor in the air .

2. Transfer process mass, that is a process that occurs because of the dryer's relative humidity is lower from the material's relative humidity, the heat flowing above materials' surface will increase its water vapor so that the determination of water vapor will be higher from pressure steam air to dryer.

In the drying process, there are two processes, namely: at the beginning of the process, the water on the surface of the material will be evaporated as depicted on the drying curve which has a low slope then the process of transferring water from the material in the surface to the water bound to the material applies.

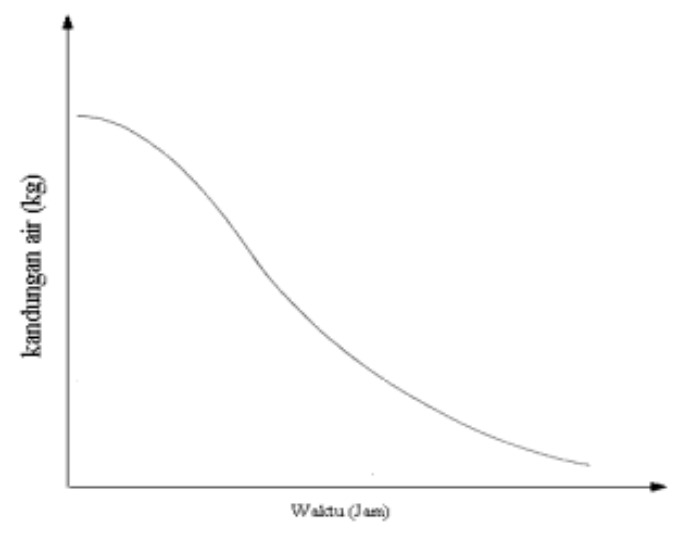

Fig. 1. Drying Curves

Another important curve explaining drying levels mechanism better is the drying levels curve, like shown on picture 3.3 it depicts the levels of change of the material's water content to its initial water content. 


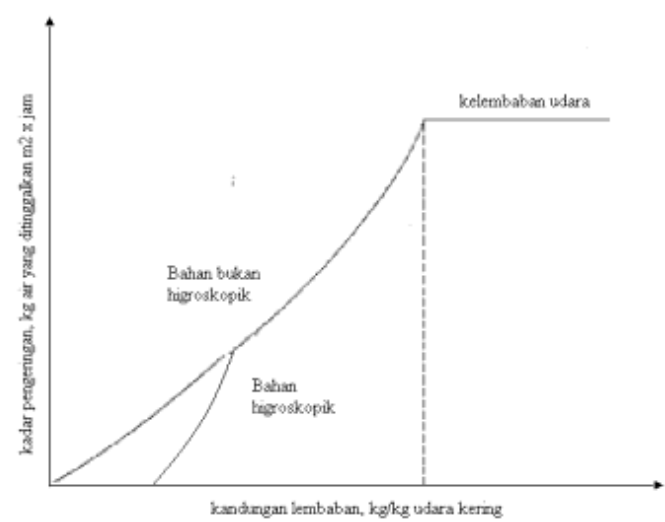

Fig. 2. Drying Level Curves

\section{RESEARCH METHODOLOGY}

A. Test Equipment Design

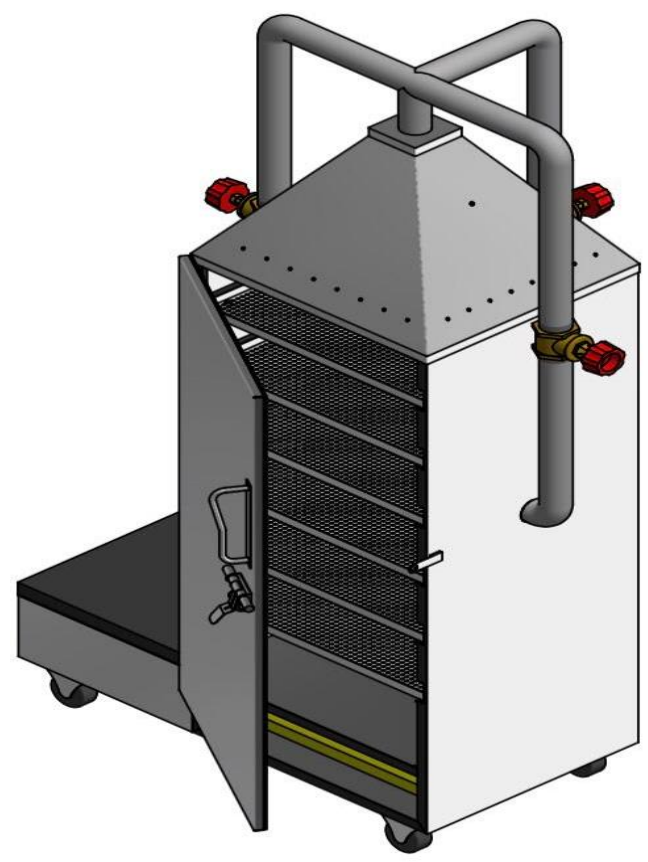

Fig. 3. Test Equipment Design

\section{B. The Measured variables and how to measure it}

The variable measured in this study is the temperature in the dryer at 30 different place positions. At the temperature measurement at 30 positions it will be examined from several variations of the air flow system in the drying system by varying the distribution of hot air flow using the on / off valve, as shown in Fig 3.

\section{Data Analysis}

The obtained temperature data will be processed with Microsof Excel to be used as graph, so that the temperature difference that occurs at 30 position measurement points can be easily seen and in some variations of the planned air flow system and heat source, so that an even air circulation system is obtained on each level of the tumpeng drying machine rack.

\section{EXPERIMENT RESULT}

\section{A. The Condition of Dryer Room in a Non-distributed Hot Air} Position

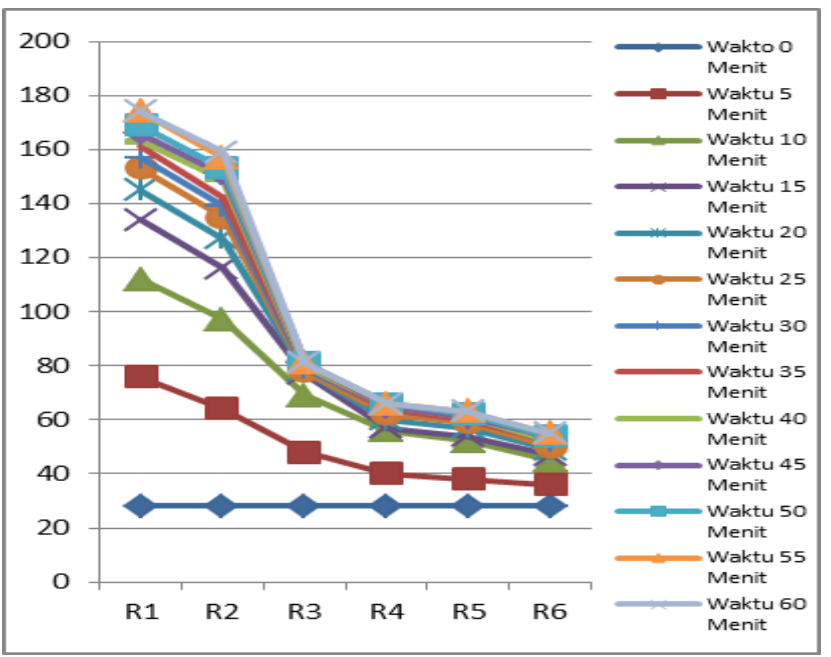

Fig. 4. Condition of the Drying Room in a Non-Distributed Hot Air Position

From Fig 4, it can be seen that the room temperature differences occuring on rack 1 , rack 2 and rack 3 are quite high, reaching $16^{0} \mathrm{C}$, while the differences that occur on rack 3 , rack 4 , rack 5 and rack 6 are relatively smaller, reaching $4^{0}$ C-5 ${ }^{0} \mathrm{C}$. This happens since the heat source is under rack 1 and the heat transfer between the shelves occurs due to the transfer of free convection.

B. The Condition of Dryer Room on Hot Air Position Distributed on Three Sides of the Drying Chamber.

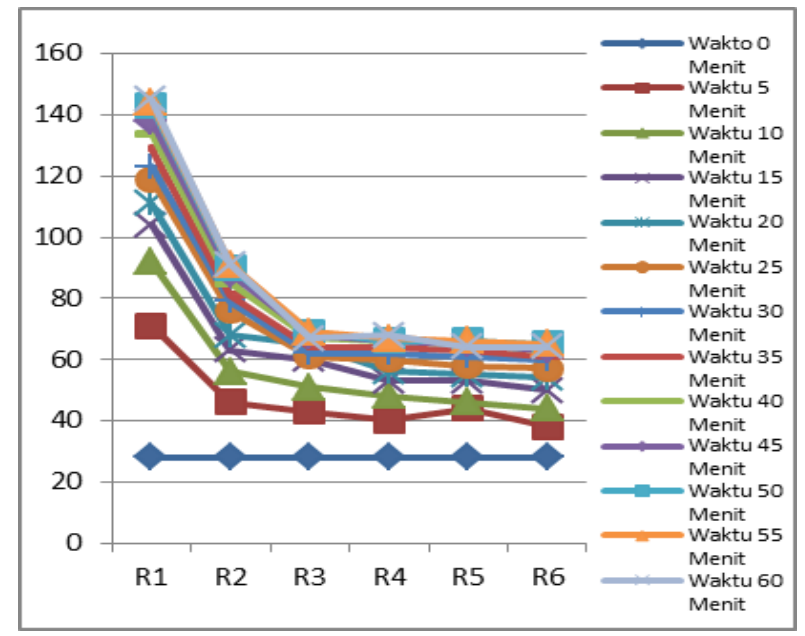

Fig. 5. Condition of Drying Room in Hot Air Position Distributed on 3 sides of the drying chamber 
The temperature in the drying chamber in hot air conditions was distributed through 3 sides of the drying chamber showing the distribution of air on the shelves $3,4,5$ and 6 was distributed fairly evenly with a difference of $1^{0} \mathrm{C}$ $30 \mathrm{C}$, but in the rack 1 and rack 2 relative temperature difference was higher, reaching $54{ }^{0} \mathrm{C}$. This happens because the position of the blower is on the upper side, so the ability of the blower to pull hot air on the shelves 1 and 2 is not optimal, so the air temperature on shelves 1 and 2 is still high.

\section{Condition of Drying Room in Hot Air Position Distributed on 2 sides of the drying chamber.}

Drying room temperature in hot air conditions distributed on 2 sides is presented in Fig 6.

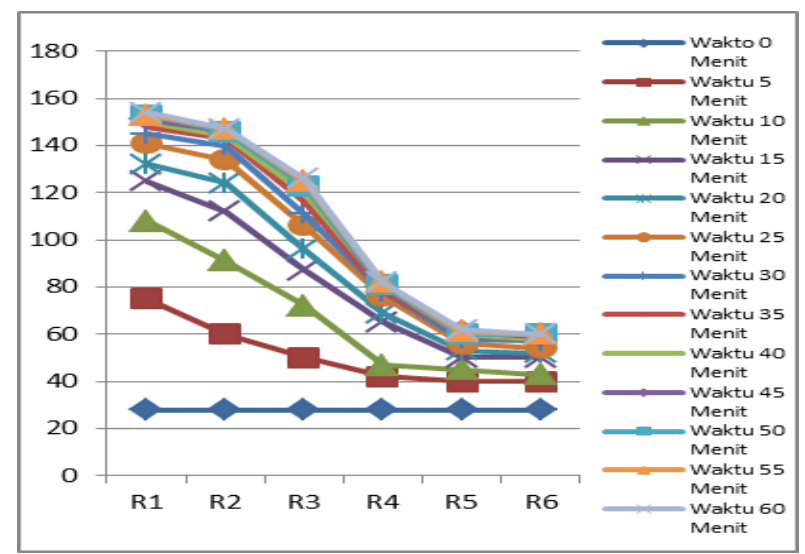

Fig. 6. Condition of Drying Room in Hot Air Position Distributed on 2 sides of the drying chamber

The temperature in the drying chamber in hot air conditions is distributed through 2 sides of the drying chamber showing the air distribution on rack 5 and rack 6 is distributed fairly evenly with a difference of $1^{0} \mathrm{C}-2^{0} \mathrm{C}$, but on rack 1 , rack 2 , rack 3 , and rack 4 the difference in temperature is still high where the difference in rack temperature 1 and rack 2 reaches $7^{0} \mathrm{C}-17^{\circ} \mathrm{C}$, the difference in rack 2 and rack 3 reaches $19^{\circ} \mathrm{C}-21^{\circ} \mathrm{C}$, the rack size 3 and rack 4 reaches $22^{0}$ $\mathrm{C}-44^{0} \mathrm{C}$ and the difference in rack 4 and rack 5 reaches $15^{0}$ $\mathrm{C}-21^{0} \mathrm{C}$. This is due to the inability of the blower to distribute the hot air in the bottom position of the drying chamber.

\section{Condition of Dryers in Hot Air Position Distributed on 1 side of drying chamber.}

In the position of the hot air is distributed through one side of the drying chamber indicating the temperature distribution in the drying chamber overflows the air distribution in the position hot air is distributed through two sides of the drying chamber where on the rack position 1 rack 5 shows a fairly high difference and the difference in rack temperature 5 and rack 6 is relatively low, more fully presented in Fig 7.

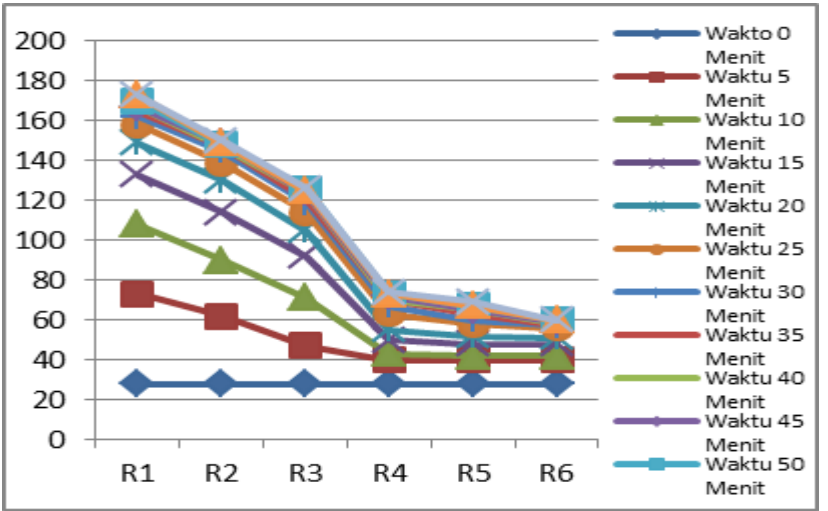

Fig. 7. Condition of Drying Room in Hot Air Position Distributed on 1 side of the drying chamber

\section{CONCLUSION}

From the results of the research conducted, it can be concluded:

1. The hot air distribution on room dryer which only rely on the convection free heat displacement is unable to evenly distribute the hot air on room dryer, although it reaches 60 minutes in period of time.

2. The distribution of hot air using the forced convection method, with the help of a blower can distribute hot air relatively better than the free correction method; however, the distribution has not been able to be optimal due to the position of the blower that is far from the heat source.

\section{REFERENCES}

[1] K. Abdulillah, Pengeringan Industrial. Penerbit IPB Press. Edisi Terjemahan: Bogor, 2000, pp. 118-120.

[2] D.B. Brooker, F.W. Bakker., and C.W. Arkema, Drying Cereal Grains. The A VI Publishing Co. Inc: West Port. USA, 1974, pp. 78 89.

[3] Y.A. Cengel and M.A. Boles, Thermodynamics: An Engineering Approach, 4 th Ed, McGraw Hill: New York, 2002.

[3] C.W. Hall, Drying and Storage of Agricultural Crops, AVI Publishing Company: Washington, 1980, pp. 134-145.

[4] R. Hasibuan, "Mekanisme Pengeringan," J. Teknik Kimia Universitas Sumatera Utara, 2004.

[5] J.P. Holman, Perpindahan Kalor, edisi keenam, Erlangga: Jakarta, 1998

[6] F.P. Incropera, Introduction of Heat Transfer, John Wiley \& Sons: New York, 1985.

[7] M.J. Moran and H.N. Shapiro, Termodinamika Teknik, jilid 1, edisi keempat, Erlangga: Jakarta, 2004.

[8] M.J. Moran and H.N. Shapiro, Termodinamika Teknik, jilid 2, edisi keempat, Erlangga: Jakarta, 2004.

[9] W.M. Rohsenow, H.Y. Choi, Heat, Mass, And Momentum Transfer, Prentice-hall, Inc: Englewood, New Jersey, 1961.

[10] T. Sato, Menggambar Mesin Menurut ISO, PT Pradnya Paramita: Jakarta, 2000.

[11] P. Singh, Introduction to Food Enginering. Academic Press: New Jersey, 2001, pp. 30-16. 